\title{
J-Integral Solutions for Surface Cracks Inside Pipes under Internal Pressure*
}

\author{
Masayuki KAMAYA** \\ **Institute of Nuclear Safety System, Inc., \\ 64 Sata, Mihama-cho, Mikata-gun, Fukui 919-1205, Japan \\ E-mail: kamaya@inss.co.jp
}

\begin{abstract}
Finite element analysis (FEA) was done for semi-elliptical axial surface cracks in pipes under internal pressure in order to provide J-integral solutions for assessing the structural integrity of cracked pipes of nuclear power plants. Elastic and fully plastic solutions were obtained for wide ranges of geometrical and material conditions. The accuracy of the J-integrals estimated using the obtained solutions was confirmed through additional FEA for non-linear elastic material under various magnitudes of pressure. The obtained solutions were shown to be valid for structural integrity assessments regardless of material and geometrical conditions and the magnitude of pressure. The maximum error in failure pressure derived using the obtained J-integral solutions was $6 \%$.
\end{abstract}

Key words: J-Integral, Stress Intensity Factor, Surface Crack, Internal Pressure, Pipe, Finite Element Method, Elastic-Plastic Analysis

\section{Introduction}

Recently, cracks due to stress corrosion cracking have been observed in primary piping of nuclear power plants in Japan. The cracks were initiated in the longitudinal direction at nickel alloy welds. Since the fracture mode of nickel alloy welding metal is not fully ductile, elastic-plastic failure has to be taken into account in the structural integrity assessment.

According to the Fitness-For-Service (FFS) code of the Japan Society of Mechanical Engineers (JSME) ${ }^{(1)}$, the failure pressure of a cracked pipe against the elastic-plastic failure is assessed based on the relationship between fracture toughness of material and the J-integral, which represents the driving force for elastic-plastic failure ${ }^{(2)-(5)}$. The FFS code suggests that the J-integral can be obtained from the handbook published by the Electric Power Research Institute (EPRI) ${ }^{(6)}$. However, the handbook gives only limited solutions particularly for surface cracks in pipes. Since the J-integral depends not only on the geometrical conditions of the pipe and crack but also on material properties such as the strain hardening exponent, it is not easy to provide extensive solutions incorporating a sufficient range of parameters for practical use. In the handbook, for axial surface cracks, there are solutions only for $R_{\mathrm{i}} / t=10$, where $R_{\mathrm{i}}$ and $t$ are inner radius and pipe thickness, respectively. Moreover, accuracy of the solutions has not been given quantitatively. Since the mesh division used for the analyses was relatively coarse, the accuracy might not be good enough ${ }^{(7)}$. Although several papers provide solutions for axial cracks ${ }^{(8)(9)}$, the number of solutions is still insufficient for assessing cracked pipes in nuclear power plant components, and validity of the solutions has not been shown.

This paper aims at providing reliable J-integral solutions for axial surface cracks in pipes under internal pressure as observed in nuclear power plants, assuming that stress 
corrosion cracking has occurred along the longitudinal direction. Extensive geometrical and material conditions are taken into account, and by performing careful finite element analyses (FEA), accurate J-integrals are obtained. Furthermore, accuracy of the obtained solutions is quantified using FEA results for various magnitudes of pressure, material and geometry conditions.

\section{J-integral estimation scheme based on fully plastic solutions}

A procedure for estimating J-integrals from obtained FEA solutions is described briefly. Here, a fully plastic material is assumed, for which strain $\varepsilon$ is related to the stress $\sigma$ in uniaxial tension by:

$$
\frac{\varepsilon}{\varepsilon_{\mathrm{o}}}=\alpha\left(\frac{\sigma}{\sigma_{\mathrm{o}}}\right)^{n}
$$

where $\varepsilon_{\mathrm{o}}$ and $\sigma_{\mathrm{o}}$ are normalization stress and strain, $n$ is the strain hardening exponent and $\alpha$ is a material constant. When the yield strength $\sigma_{\mathrm{y}}$ and corresponding strain $\sigma_{\mathrm{y}} / E$ ( $E$ : Young's modulus) are used for the normalization stress and strain, the J-integral for this material, $J_{\mathrm{p}}$, can be expressed as Eq. (2). ${ }^{(10)(11)}$

$$
J_{\mathrm{p}}=h_{1} \frac{\alpha \sigma_{\mathrm{y}}^{2} t}{E}\left(\frac{P}{P_{\mathrm{L}}}\right)^{n+1}
$$

$P$ and $P_{\mathrm{L}}$ denote the applied internal pressure and the limit pressure for the cracked pipe, and $h_{1}$ is a constant depending on geometrical and material conditions. Once $h_{1}$ has been obtained, the J-integral can be estimated for an arbitrary pressure. In order to simulate the stress-strain relation of engineering materials used for nuclear power plants, the Ramberg-Osgood (R-O) relation is assumed in this study:

$$
\frac{\varepsilon}{\varepsilon_{\mathrm{y}}}=\frac{\sigma}{\sigma_{\mathrm{y}}}+\alpha\left(\frac{\sigma}{\sigma_{\mathrm{y}}}\right)^{n}
$$

The J-integral is then obtained by ${ }^{(12)}$ :

$$
J=J_{\mathrm{e}}+J_{\mathrm{p}}=\frac{\left(K\left(a_{\mathrm{e}}\right)\right)^{2}}{E^{\prime}}+h_{1} \frac{\alpha \sigma_{\mathrm{y}}^{2} t}{E}\left(\frac{P}{P_{\mathrm{L}}}\right)^{n+1}
$$

where $E^{\prime}=E /\left(1-v^{2}\right)\left(v\right.$ : Poisson's ratio) and $K\left(a_{\mathrm{e}}\right)$ is the stress intensity factor (SIF) represented by Eq. (5).

$$
K\left(a_{\mathrm{e}}\right)=f_{1} P \frac{R_{\mathrm{m}}}{t} \sqrt{\pi a_{\mathrm{e}}}
$$

$R_{\mathrm{m}}$ is the mean radius of the pipe, $f_{1}$ is a constant, which depends on the geometrical conditions, and $a_{\mathrm{e}}$ is the crack depth modified in order to incorporate the effect of plastic deformation near the crack tip. Kumar and Shih ${ }^{(13)}$ proposed the following equation for the crack of depth of $a$ : 


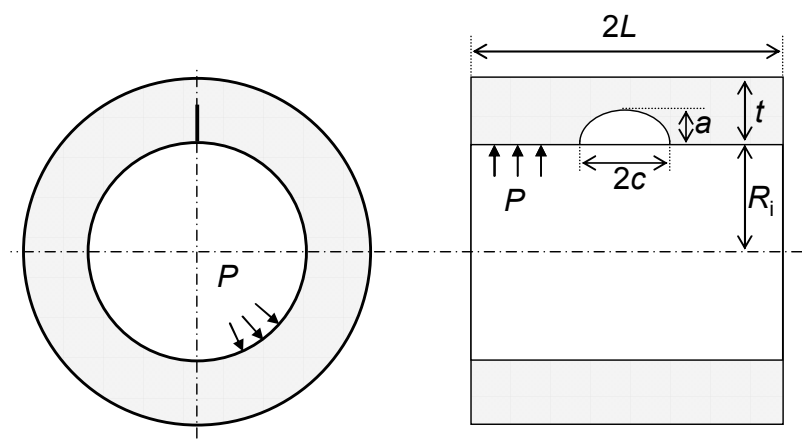

Fig. 1 Geometry of pipe with axial crack under internal pressure.

$$
a_{\mathrm{e}}=a+\frac{1}{6 \pi} \frac{(n-1)}{(n+1)}\left(\frac{K(a)}{\sigma_{\mathrm{y}}}\right)^{2}\left(\frac{1}{1+\left(P / P_{\mathrm{L}}\right)^{2}}\right)
$$

By preparing the constants $h_{1}$ and $f_{1}$, the J-integral for an arbitrary pressure can be obtained. It should be noted that Eq. (6) was derived semi-empirically, although Eq. (6) together with Eq. (4) provide the precise J-integral for some conditions ${ }^{(12)(13)}$. Therefore, it is important to confirm the validity of the plastic correction $a_{\mathrm{e}}$ particularly for the transient region between elastic and plastic. In the previous study by the author for circumferential cracks under bending load ${ }^{(14)}$, the correction by Eq. (6) did not give good J-integral estimation and an alternative correction factor was proposed.

In this study, the estimated J-integrals were compared with those for R-O material, whose stress-strain relation was expressed by Eq. (3) in order to confirm the validity of the current J-integral estimation scheme using Eqs. (4) and (6). Since the magnitude of the applied internal pressure could not be normalized for the R-O material, the calculation has to be carried out for each pressure condition. Five levels of applied pressure were assumed, and therefore, five times as many calculations as those for obtaining the solution were carried out only for the sake of validation. Through the careful validation, it was possible to provide reliable solutions, which was the primary objective of this study.

\section{Finite element analysis}

\subsection{Analysis conditions}

In this study, a pipe with an axial inner surface crack subjected to an internal pressure $P$ was assumed. The crack had a semi-elliptical shape and was located parallel to the longitudinal direction of the pipe as shown in Fig. 1. The limit pressure $P_{\mathrm{L}}$ for the cracked pipe was obtained by the following equation according to the JSME FFS code ${ }^{(1)}$ :

$$
\begin{aligned}
& P_{\mathrm{L}}=\frac{t}{R_{\mathrm{m}}} \sigma_{\mathrm{y}}\left(\frac{t / a-1}{t / a-1 / M_{\mathrm{t}}}\right) \\
& M_{\mathrm{t}}=\sqrt{1+\frac{1.61 c^{2}}{R_{\mathrm{m}} t}}
\end{aligned}
$$

where $c$ is half the surface length of the crack. 


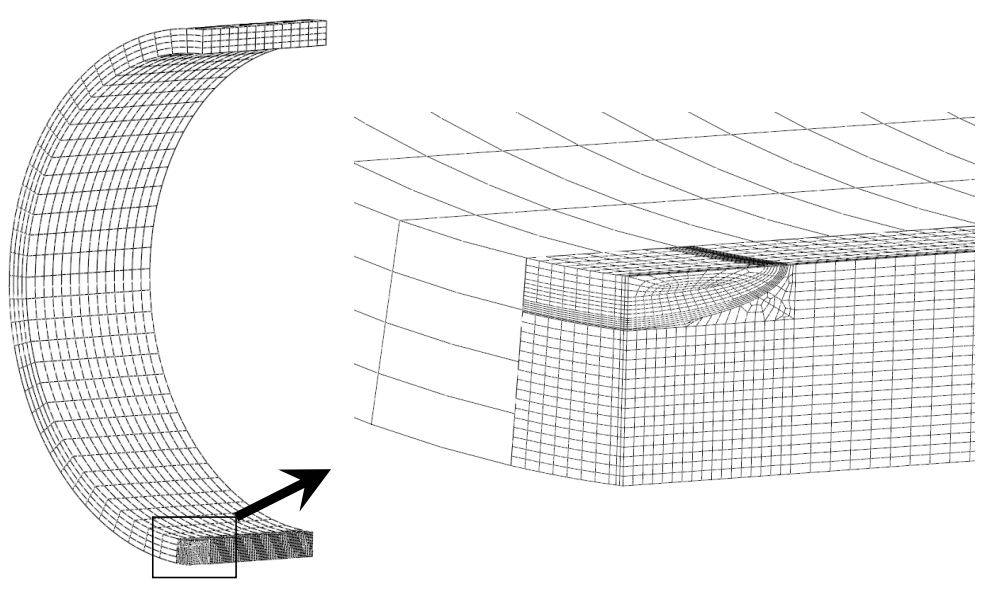

Fig. 2 Example of finite element mesh $\left(R_{\mathrm{m}} / t=10, a / t=0.2, a / c=0.2\right)$.

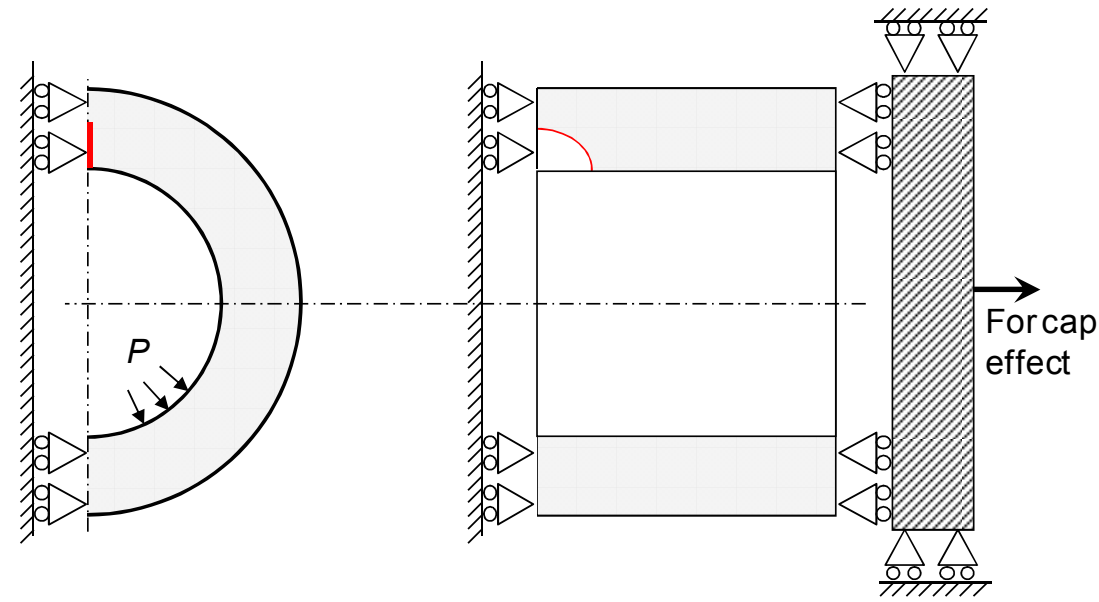

Fig. 3 Boundary conditions of cracked pipe under internal pressure.

J-integrals and SIFs were evaluated by FEA under various material and geometrical conditions. To incorporate various materials used in nuclear power plant components, five values of strain hardening exponent were assumed: $n=3,5,7,10$ and 13 under a fixed constant of $\alpha=1.5$. The yield strength and Young's modulus were assumed to be $\sigma_{\mathrm{y}}=200$ $\mathrm{MPa}$ and $E=180 \mathrm{GPa}$, respectively, although these values were used just for normalization. Poisson's ratio was set to 0.3 .

The geometrical conditions were possible combinations of the following:

$$
\begin{aligned}
& R_{\mathrm{m}} / t=5,10,20 \\
& a / t=0.05,0.1,0.15,0.2,0.25,0.3,0.35,0.4,0.45,0.5,0.55,0.6,0.65,0.7,0.75 \\
& c / a=0.1,0.2,0.3,0.4,0.5,0.6,0.7,0.8,0.9,1.0
\end{aligned}
$$

The pipe thickness $t$ was assumed to be $40 \mathrm{~mm}$. It was previously confirmed that pipe thickness (diameter) has no influence on the J-integral in the current estimation scheme (14)(15).

\subsection{Analysis procedure}

FEA was carried out using the general-purpose finite element program ABAQUS, Version 6.9. Figure 2 shows an example of the finite element model for the conditions of 


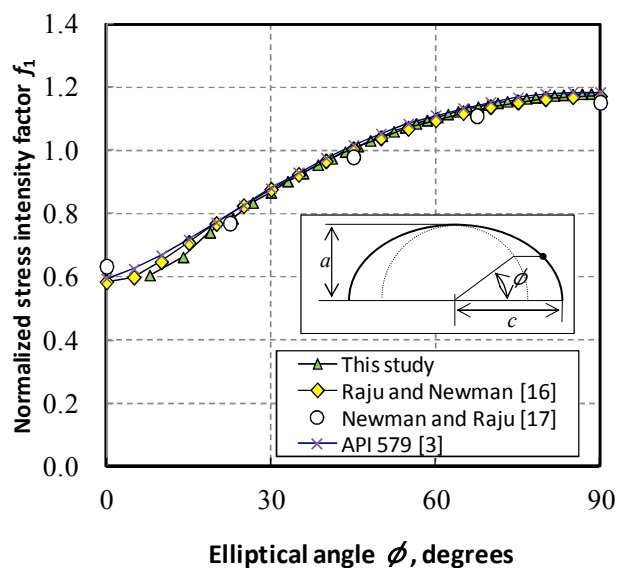

Fig. 4 Stress intensity factor for surface $\operatorname{crack}\left(R_{\mathrm{i}} / t=10, a / t=0.2, a / c=0.2\right)$.

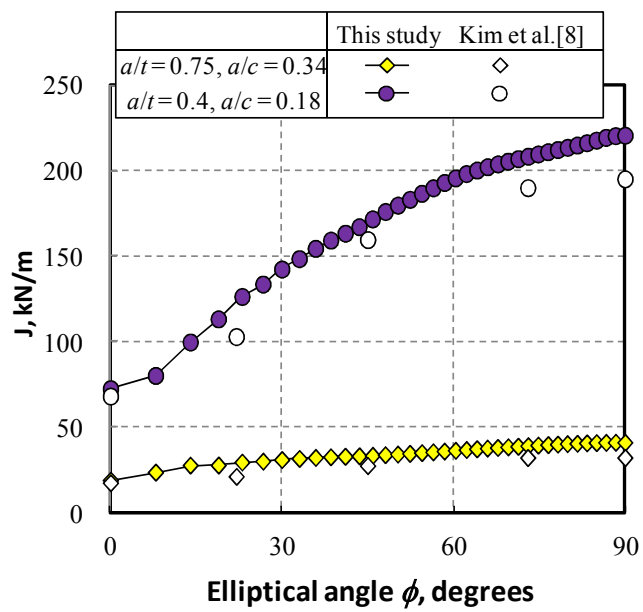

(a) $P / P_{\mathrm{L}}=1.5$

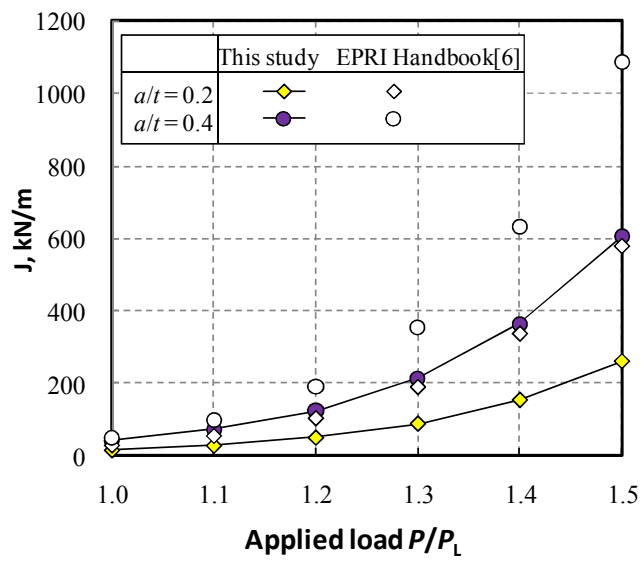

Fig. 5 Change in J-integral with internal pressure $\left(\phi=90^{\circ}, R_{\mathrm{i}} / t=10, a / c=0.2, n=7\right)$.

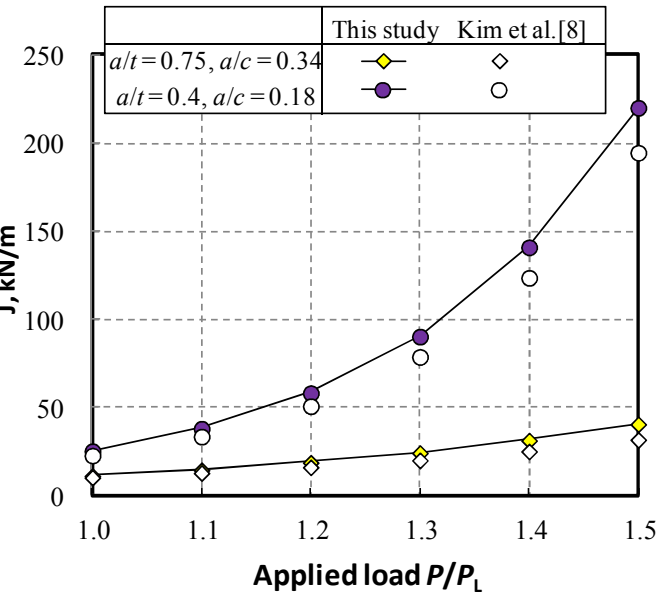

(b) $\phi=90^{\circ}$

Fig. $6 \mathrm{~J}$-integral at deepest point with internal pressure $\left(\phi=90^{\circ}, R_{\mathrm{i}} / t=10, n=7\right.$, with cap effect).

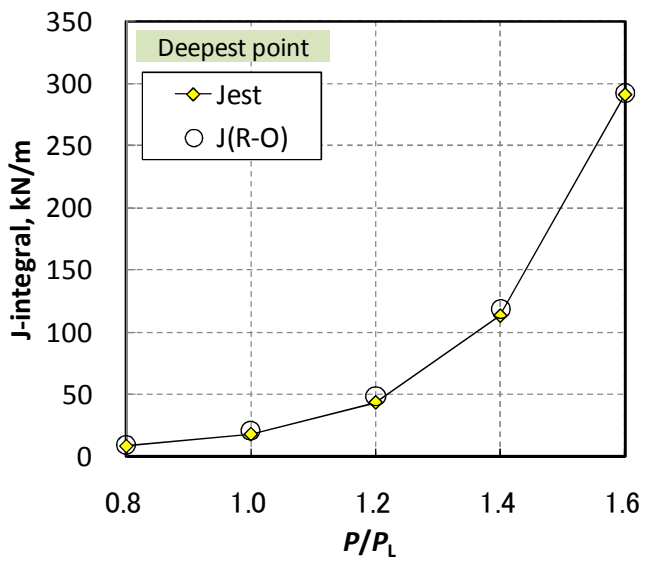

(a) $\phi=90^{\circ}$

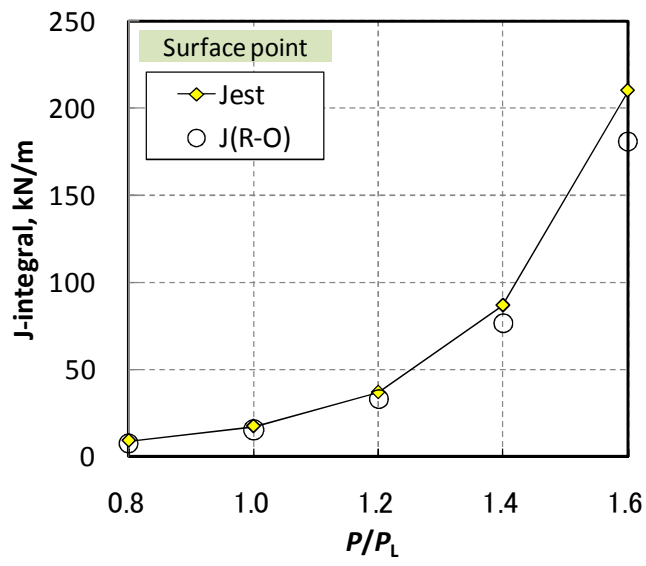

(b) $\phi=3.8^{\circ}$

Fig. 7 Obtained J-integral solutions $\left(R_{\mathrm{m}} / t=10, a / t=0.2, a / c=0.2, n=7\right)$.

$R_{\mathrm{m}} / t=10, a / t=0.2$ and $a / c=0.2$. The 20-node isoparametric quadratic solid elements with reduced integration were used. Due to the symmetries of the problem, only one quarter of the cracked pipe was modeled by finite elements as shown in Fig. 3. The displacement boundary conditions were applied to the planes of the symmetries. The half length of the 


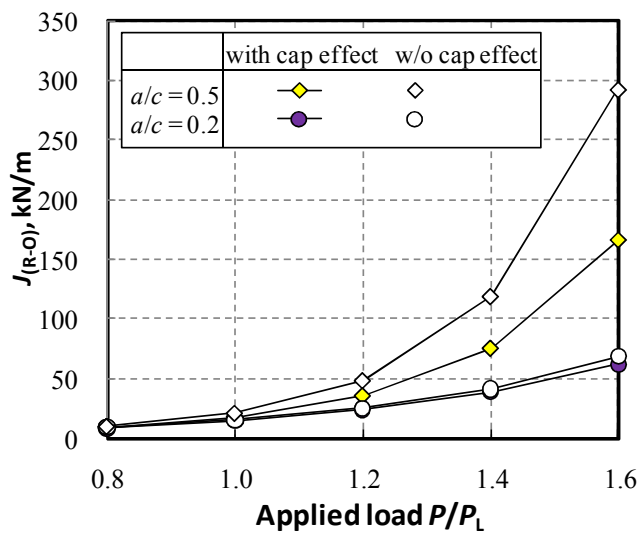

Fig. 8 Influence of cap effect on J-integral $\left(R_{\mathrm{m}} / t=10, a / t=0.75\right)$.

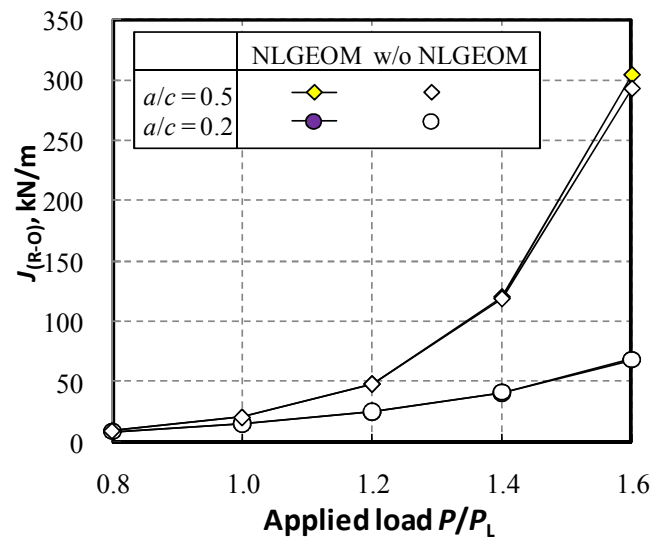

Fig.9 Influence of analysis procedure $\left(R_{\mathrm{m}} / t=10, a / t=0.75\right)$.

finite element model was set to $L=7 c$ in order to suppress the edge effect. The internal pressure was applied inside the pipe including the crack face. In several analyses, axial load was applied to end of the pipe in order to simulate the "cap effect" by the internal pressure. In ABAQUS, the SIF and J-integral are derived from the energy release rate, which is obtained by the virtual crack extension integral method. The finite element model had 37 nodes along the crack front and the SIF and J-integral were evaluated at each node from the mean of the $3 \mathrm{rd}$, 4th and 5th contours; the 1st and 2 nd contours were neglected due to poor accuracy.

Elastic and elastic-plastic FEA were performed in order to derive the constants $f_{1}$ and $h_{1}$, respectively. The fully plastic material behavior, which was expressed by Eq. (1), was simulated by a poly-linear stress-strain curve with large Young's modulus ( $3-100 \mathrm{TPa})$. The constant $h_{1}$ was calculated from Eq. (2) based on the evaluated J-integral obtained under the internal pressure of $P=P_{\mathrm{L}}$. J-integrals were also calculated assuming the R-O non-linear elastic material. By comparing the J-integrals from Eq. (4) and the direct calculation assuming the R-O relation, it was possible to show the validity of evaluated constants $f_{1}$ and $h_{1}$ together with Eq. (4) and the crack depth correction by Eq. (6).

\subsection{Comparison with reference data}

The SIF shown in Fig. 4 was obtained for a crack of $a / t=0.2, a / c=0.2$ in a pipe of $R_{\mathrm{i}} / t$ $=10$. The obtained SIFs along the crack were almost identical to those from reference data.

Figure 5 compares the J-integral of R-O material at the deepest point obtained by the current analyses and EPRI handbook data ${ }^{(6)}$. The J-integral from the EPRI handbook data was almost twice that from the current analyses. Therefore, conservative integrity assessment can be performed by using the J-integral of the EPRI handbook, if the current J-integral analysis was correct. As mentioned above, the accuracy of the J-integral of the EPRI handbook has not been shown, and it did not seem to be good due to the coarse finite element mesh. Furthermore, detailed calculation conditions such as FEA procedures, mesh type and how the cap effect was treated were not given.

The J-integral solutions by Kim et al. ${ }^{(8)}$ are shown in Fig. 6. They did careful FEA using a fine mesh and the analysis conditions were described in detail. The same analyses were carried out by the current analysis procedure, and as shown in Fig. 6, the results agreed well with those given by Kim et al. along the crack front and at the deepest point under various applied pressures. 
Table 1 Constants $f_{1}$ values for stress intensity factors.

\begin{tabular}{|c|c|c|c|c|c|c|c|c|c|c|c|c|c|c|c|c|c|}
\hline & \multirow{2}{*}{$R_{\mathrm{m}}$} & \multirow{2}{*}{$a / c$} & \multicolumn{15}{|c|}{$a / t$} \\
\hline & & & 0.05 & 0.10 & 0.15 & 0.20 & 0.25 & 0.30 & 0.35 & 0.40 & 0.45 & 0.50 & 0.55 & 0.60 & 0.65 & 0.70 & 0.75 \\
\hline \multirow{30}{*}{ 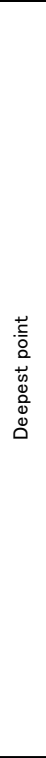 } & \multirow{10}{*}{5} & 0.1 & 1.29 & 1.30 & 1.32 & 1.36 & 1.42 & 1.50 & 1.59 & 1.69 & 1.81 & 1.94 & 2.09 & 2.25 & 2.42 & 2.60 & 2.79 \\
\hline & & 0.2 & 1.24 & 1.23 & 1.24 & 1.26 & 1.28 & 1.32 & 1.37 & 1.43 & 1.49 & 1.56 & 1.64 & 1.73 & 1.82 & 1.92 & 2.03 \\
\hline & & 0.3 & 1.17 & 1.17 & 1.16 & 1.17 & 1.19 & 1.21 & 1.23 & 1.26 & 1.30 & 1.34 & 1.39 & 1.44 & 1.49 & 1.55 & 1.61 \\
\hline & & 0.4 & 1.11 & 1.10 & 1.10 & 1.10 & 1.11 & 1.12 & 1.13 & 1.15 & 1.17 & 1.20 & 1.22 & 1.25 & 1.28 & 1.32 & 1.36 \\
\hline & & 0.5 & 1.05 & 1.04 & 1.03 & 1.03 & 1.03 & 1.04 & 1.05 & 1.06 & 1.07 & 1.08 & 1.10 & 1.12 & 1.14 & 1.16 & 1.19 \\
\hline & & 0.6 & 0.983 & 0.979 & 0.973 & 0.970 & 0.970 & 0.972 & 0.975 & 0.981 & 0.987 & 1.00 & 1.01 & 1.02 & 1.03 & 1.04 & 1.06 \\
\hline & & 0.7 & 0.926 & 0.922 & 0.916 & 0.912 & 0.910 & 0.910 & 0.911 & 0.914 & 0.917 & 0.921 & 0.927 & 0.933 & 0.941 & 0.950 & 0.962 \\
\hline & & 0.8 & 0.873 & 0.869 & 0.864 & 0.859 & 0.856 & 0.855 & 0.854 & 0.855 & 0.856 & 0.858 & 0.861 & 0.864 & 0.869 & 0.875 & 0.883 \\
\hline & & 0.9 & 0.824 & 0.821 & 0.816 & 0.811 & 0.808 & 0.805 & 0.803 & 0.803 & 0.802 & 0.803 & 0.804 & 0.805 & 0.808 & 0.811 & 0.817 \\
\hline & & 1.0 & 0.779 & 0.777 & 0.771 & 0.767 & 0.763 & 0.760 & 0.758 & 0.756 & 0.755 & 0.754 & 0.754 & 0.754 & 0.755 & 0.757 & 0.761 \\
\hline & \multirow{10}{*}{10} & 0.1 & 1.18 & 1.20 & 1.23 & 1.28 & 1.34 & 1.41 & 1.50 & 1.61 & 1.73 & 1.86 & 2.01 & 2.17 & 2.34 & 2.52 & 2.70 \\
\hline & & 0.2 & 1.13 & 1.14 & 1.15 & 1.18 & 1.21 & 1.25 & 1.30 & 1.36 & 1.42 & 1.49 & 1.56 & 1.64 & 1.72 & 1.80 & 1.87 \\
\hline & & 0.3 & 1.07 & 1.08 & 1.09 & 1.10 & 1.12 & 1.14 & 1.17 & 1.21 & 1.25 & 1.29 & 1.33 & 1.37 & 1.41 & 1.45 & 1.49 \\
\hline & & 0.4 & 1.01 & 1.02 & 1.03 & 1.03 & 1.04 & 1.06 & 1.08 & 1.10 & 1.12 & 1.15 & 1.17 & 1.20 & 1.22 & 1.24 & 1.27 \\
\hline & & 0.5 & 0.956 & 0.960 & 0.963 & 0.967 & 0.975 & 0.984 & 1.00 & 1.01 & 1.03 & 1.04 & 1.06 & 1.07 & 1.09 & 1.10 & 1.11 \\
\hline & & 0.6 & 0.907 & 0.900 & 0.904 & 0.907 & 0.912 & 0.919 & 0.927 & 0.936 & 0.946 & 0.956 & 0.966 & 0.975 & 0.984 & 0.993 & 1.00 \\
\hline & & 0.7 & 0.854 & 0.848 & 0.850 & 0.853 & 0.856 & 0.860 & 0.865 & 0.871 & 0.877 & 0.884 & 0.890 & 0.896 & 0.902 & 0.907 & 0.914 \\
\hline & & 0.8 & 0.805 & 0.799 & 0.801 & 0.803 & 0.805 & 0.807 & 0.810 & 0.814 & 0.818 & 0.822 & 0.826 & 0.830 & 0.833 & 0.837 & 0.841 \\
\hline & & 0.9 & 0.760 & 0.754 & 0.756 & 0.757 & 0.758 & 0.760 & 0.762 & 0.764 & 0.766 & 0.769 & 0.771 & 0.773 & 0.775 & 0.777 & 0.780 \\
\hline & & 1.0 & 0.719 & 0.714 & 0.715 & 0.716 & 0.716 & 0.717 & 0.718 & 0.719 & 0.720 & 0.721 & 0.722 & 0.723 & 0.724 & 0.725 & 0.727 \\
\hline & \multirow{10}{*}{20} & 0.1 & 1.13 & 1.14 & 1.18 & 1.23 & 1.29 & 1.37 & 1.46 & 1.56 & 1.68 & 1.81 & 1.95 & 2.10 & 2.26 & 2.43 & 2.59 \\
\hline & & 0.2 & 1.08 & 1.08 & 1.11 & 1.14 & 1.17 & 1.22 & 1.27 & 1.33 & 1.39 & 1.46 & 1.53 & 1.60 & 1.66 & 1.73 & 1.79 \\
\hline & & 0.3 & 1.02 & 1.03 & 1.04 & 1.06 & 1.08 & 1.11 & 1.14 & 1.18 & 1.22 & 1.26 & 1.30 & 1.34 & 1.37 & 1.40 & 1.43 \\
\hline & & 0.4 & 0.991 & 0.973 & 0.983 & 1.00 & 1.01 & 1.03 & 1.05 & 1.08 & 1.10 & 1.13 & 1.15 & 1.17 & 1.19 & 1.21 & 1.23 \\
\hline & & 0.5 & 0.933 & 0.915 & 0.923 & 0.932 & 0.943 & 0.956 & 0.971 & 0.987 & 1.00 & 1.02 & 1.04 & 1.05 & 1.06 & 1.07 & 1.08 \\
\hline & & 0.6 & 0.927 & 0.869 & 0.864 & 0.871 & 0.880 & 0.890 & 0.901 & 0.912 & 0.924 & 0.935 & 0.946 & 0.956 & 0.964 & 0.971 & 0.977 \\
\hline & & 0.7 & 0.872 & 0.818 & 0.813 & 0.818 & 0.825 & 0.832 & 0.840 & 0.848 & 0.856 & 0.864 & 0.871 & 0.878 & 0.883 & 0.888 & 0.891 \\
\hline & & 0.8 & 0.821 & 0.771 & 0.766 & 0.770 & 0.775 & 0.781 & 0.787 & 0.793 & 0.798 & 0.804 & 0.808 & 0.813 & 0.816 & 0.819 & 0.821 \\
\hline & & 0.9 & 0.774 & 0.728 & 0.723 & 0.726 & 0.730 & 0.735 & 0.739 & 0.743 & 0.747 & 0.751 & 0.754 & 0.757 & 0.759 & 0.760 & 0.762 \\
\hline & & 1.0 & 0.730 & 0.688 & 0.683 & 0.686 & 0.690 & 0.693 & 0.696 & 0.700 & 0.702 & 0.705 & 0.707 & 0.708 & 0.709 & 0.710 & 0.711 \\
\hline \multirow{30}{*}{ 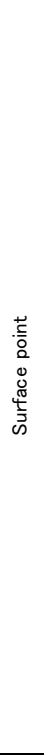 } & \multirow{20}{*}{10} & 0.1 & 0.542 & 0.537 & 0.550 & 0.566 & 0.585 & 0.607 & 0.632 & 0.660 & 0.692 & 0.727 & 0.767 & 0.812 & 0.861 & 0.916 & 0.976 \\
\hline & & 0.2 & 0.631 & 0.636 & 0.645 & 0.661 & 0.681 & 0.705 & 0.735 & 0.768 & 0.806 & 0.849 & 0.897 & 0.949 & 1.01 & 1.07 & 1.14 \\
\hline & & 0.3 & 0.714 & 0.720 & 0.726 & 0.738 & 0.755 & 0.777 & 0.803 & 0.834 & 0.870 & 0.909 & 0.954 & 1.00 & 1.05 & 1.11 & 1.17 \\
\hline & & 0.4 & 0.787 & 0.788 & 0.792 & 0.801 & 0.815 & 0.834 & 0.858 & 0.886 & 0.918 & 0.955 & 1.000 & 1.04 & 1.09 & 4 & 1.20 \\
\hline & & 0.5 & 0.832 & 0.833 & 0.834 & 0.840 & 0.851 & 0.866 & 0.885 & 0.908 & 0.935 & 0.965 & 1.000 & 1.04 & 1.08 & 1.12 & 1.16 \\
\hline & & 0.6 & 0.868 & 0.866 & 0.866 & 0.870 & 0.878 & 0.890 & 0.905 & 0.924 & 0.947 & 0.973 & 1.000 & 1.03 & 1.07 & 1.10 & 1.14 \\
\hline & & 0.7 & 0.883 & 0.882 & 0.881 & 0.883 & 0.889 & 0.898 & 0.910 & 0.926 & 0.944 & 0.965 & 0.989 & 1.01 & 1.04 & 1.07 & 1.10 \\
\hline & & 0.8 & 0.890 & 0.889 & 0.888 & 0.889 & 0.893 & 0.900 & 0.910 & 0.922 & 0.937 & 0.955 & 0.974 & 1.00 & 1.02 & 1.04 & 1.07 \\
\hline & & 0.9 & 0.891 & 0.890 & 0.889 & 0.889 & 0.892 & 0.897 & 0.905 & 0.915 & 0.927 & 0.942 & 0.958 & 0.975 & 0.994 & 1.01 & 1.03 \\
\hline & & 1.0 & 0.888 & 0.887 & 0.886 & 0.886 & 0.888 & 0.892 & 0.898 & 0.906 & 0.916 & 0.928 & 0.941 & 0.956 & 0.972 & 0.988 & 1.01 \\
\hline & & 0.1 & 0.506 & 0.507 & 0.507 & 0.516 & 0.532 & 0.553 & 0.577 & 0.605 & 0.637 & 0.673 & 0.715 & 0.764 & 0.819 & 0.882 & 0.954 \\
\hline & & 0.2 & 0.570 & 0.583 & 0.593 & 0.607 & 0.625 & 0.648 & 0.675 & 0.707 & 0.744 & 0.786 & 0.833 & 0.887 & 0.946 & 1.01 & 1.08 \\
\hline & & 0.3 & 0.644 & 0.656 & 0.667 & 0.681 & 0.698 & 0.720 & 0.745 & 0.775 & 0.809 & 0.848 & 0.890 & 0.937 & 0.989 & 1.04 & 1.10 \\
\hline & & 0.4 & 0.713 & 0.723 & 0.730 & 0.741 & 0.756 & 0.776 & 0.799 & 0.827 & 0.858 & 0.893 & 0.932 & 0.974 & 1.02 & 1.07 & 1.12 \\
\hline & & 0.5 & 0.756 & 0.764 & 0.770 & 0.778 & 0.791 & 0.807 & 0.827 & 0.851 & 0.878 & 0.908 & 0.941 & 0.976 & 1.01 & 1.05 & 1.09 \\
\hline & & 0.6 & 0.791 & 0.796 & 0.801 & 0.807 & 0.817 & 0.830 & 0.847 & 0.867 & 0.890 & 0.916 & 0.945 & 0.975 & 1.01 & 1.04 & 1.08 \\
\hline & & 0.7 & 0.809 & 0.810 & 0.814 & 0.819 & 0.827 & 0.838 & 0.852 & 0.869 & 0.889 & 0.911 & 0.935 & 0.960 & 0.987 & 1.02 & 1.04 \\
\hline & & 0.8 & 0.820 & 0.816 & 0.819 & 0.824 & 0.830 & 0.840 & 0.851 & 0.865 & 0.882 & 0.900 & 0.921 & 0.943 & 0.965 & 0.989 & 1.01 \\
\hline & & 0.9 & 0.827 & 0.816 & 0.819 & 0.823 & 0.829 & 0.837 & 0.847 & 0.859 & 0.872 & 0.888 & 0.905 & 0.924 & 0.943 & 0.963 & 0.984 \\
\hline & & 1.0 & 0.831 & 0.813 & 0.816 & 0.819 & 0.824 & 0.831 & 0.839 & 0.849 & 0.861 & 0.874 & 0.889 & 0.905 & 0.921 & 0.938 & 0.956 \\
\hline & & 0.1 & 0.470 & 0.491 & 0.500 & 0.508 & 0.518 & 0.531 & 0.550 & 0.574 & 0.603 & 0.638 & 0.680 & 0.728 & 0.784 & 0.849 & 0.924 \\
\hline & & 0.2 & 0.538 & 0.548 & 0.563 & 0.580 & 0.599 & 0.621 & 0.647 & 0.677 & 0.711 & 0.751 & 0.796 & 0.847 & 0.904 & 0.967 & 1.04 \\
\hline & & 0.3 & 0.631 & 0.619 & 0.631 & 0.647 & 0.666 & 0.689 & 0.715 & 0.745 & 0.779 & 0.816 & 0.858 & 0.904 & 0.953 & 1.01 & 1.06 \\
\hline & & 0.4 & 0.674 & 0.684 & 0.696 & 0.709 & 0.725 & 0.745 & 0.769 & 0.797 & 0.829 & 0.864 & 0.902 & 0.944 & 0.988 & 1.03 & 1.08 \\
\hline & & 0.5 & 0.729 & 0.724 & 0.734 & 0.745 & 0.759 & 0.776 & 0.797 & 0.821 & 0.849 & 0.879 & 0.913 & 0.948 & 0.986 & 1.02 & 1.06 \\
\hline & 24 & 0.6 & 0.777 & 0.757 & 0.764 & 0.774 & 0.786 & 0.800 & 0.818 & 0.839 & 0.863 & 0.889 & 0.918 & 0.949 & 0.981 & 1.01 & 1.05 \\
\hline & & 0.7 & 0.807 & 0.775 & 0.777 & 0.785 & 0.795 & 0.808 & 0.823 & 0.840 & 0.861 & 0.883 & 0.908 & 0.934 & 0.962 & 0.990 & 1.02 \\
\hline & & 0.8 & 0.828 & 0.786 & 0.783 & 0.789 & 0.797 & 0.808 & 0.821 & 0.837 & 0.854 & 0.873 & 0.894 & 0.917 & 0.940 & 0.964 & 0.988 \\
\hline & & 0.9 & 0.842 & 0.793 & 0.784 & 0.788 & 0.795 & 0.805 & 0.816 & 0.829 & 0.844 & 0.861 & 0.879 & 0.898 & 0.918 & 0.938 & 0.959 \\
\hline & & 1.0 & 0.848 & 0.796 & 0.783 & 0.784 & 0.790 & 0.798 & 0.808 & 0.820 & 0.833 & 0.847 & 0.862 & 0.879 & 0.896 & 0.914 & 0.931 \\
\hline
\end{tabular}

\section{Analysis results}

\subsection{J-integrals estimated by $f_{1}$ and $h_{1}$}

Based on the obtained $f_{1}$ and $h_{1}$, J-integrals for R-O materials were estimated according to Eqs. (4) and (6). Figure 7 compares the estimated J-integrals, $J_{\mathrm{est}}=J_{\mathrm{e}}+J_{\mathrm{p}}$, and those obtained from FEA for the R-O material, $J_{(\mathrm{R}-\mathrm{O})}$. The value at $\phi=3.8^{\circ}$ was taken as that at the surface point instead of that at $\phi=0^{\circ}$ in order to avoid the influence of peculiar singularity on the surface. The geometrical and material conditions were $R_{\mathrm{m}} / t=10$, a/t $=$ $0.2, a / c=0.2$ and $n=7$, respectively.

$J_{\text {est }}$ agreed well with $J_{(\mathrm{R}-\mathrm{O})}$ regardless of applied pressure up to the pressure of $P=$ 1.6P $P_{\mathrm{L}}$. Therefore, the effect of applied pressure on $\mathrm{J}$-integral could be taken into account 
Table 2(a) Constants $h_{1}$ values for J-integrals $(n=3)$.

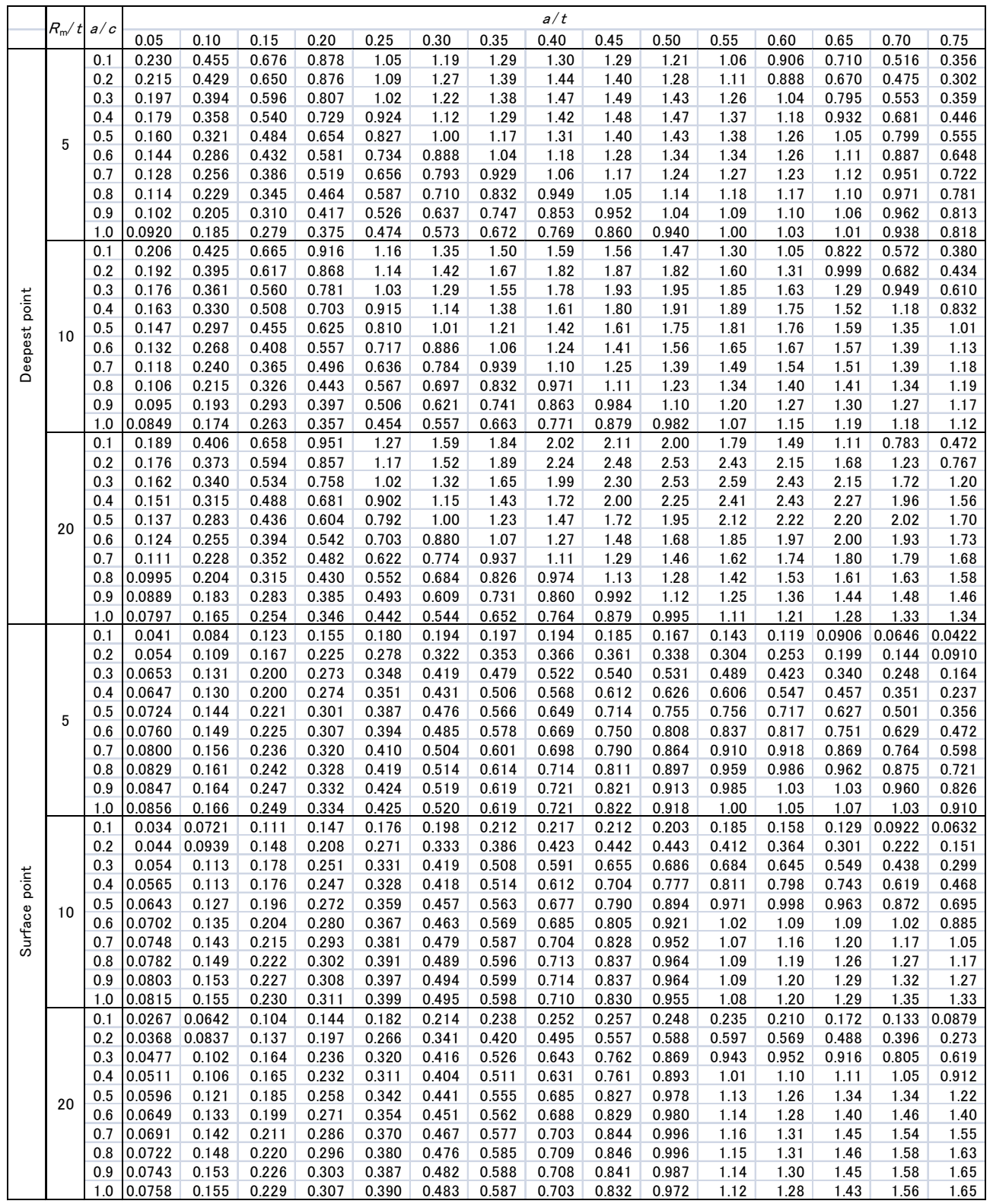

successfully by the current estimation procedure. It was shown that the plastic correction by Eq. (6) gave good approximation of the J-integral for a through-wall crack under antiplane shear loading ${ }^{(12)}$. On the other hand, in the author's previous study for circumferential surface cracks in a pipe under bending load ${ }^{(14)}$, the correction did not work well and the difference the between the $J_{\text {est }}$ and $J_{\text {(R-O) }}$ was significant particularly when the applied load was near the limit load. As for axial cracks, the correction by Eq. (6) seemed to give good estimation.

\subsection{Influence of analysis conditions}

The influence of the cap effect on J-integrals is shown in Fig. 8. The cap effect reduced J-integrals especially for large pressure. The multi-axial effect brought about by the axial stress suppressed the plastic strain. Since, in plant pipe systems, the cap effect cannot always be expected to occur due to deformation constraints, it was not considered in the following analysis in order to provide conservative J-integral solutions for structural 
Table 2(b) Constants $h_{1}$ values for J-integrals $(n=5)$.

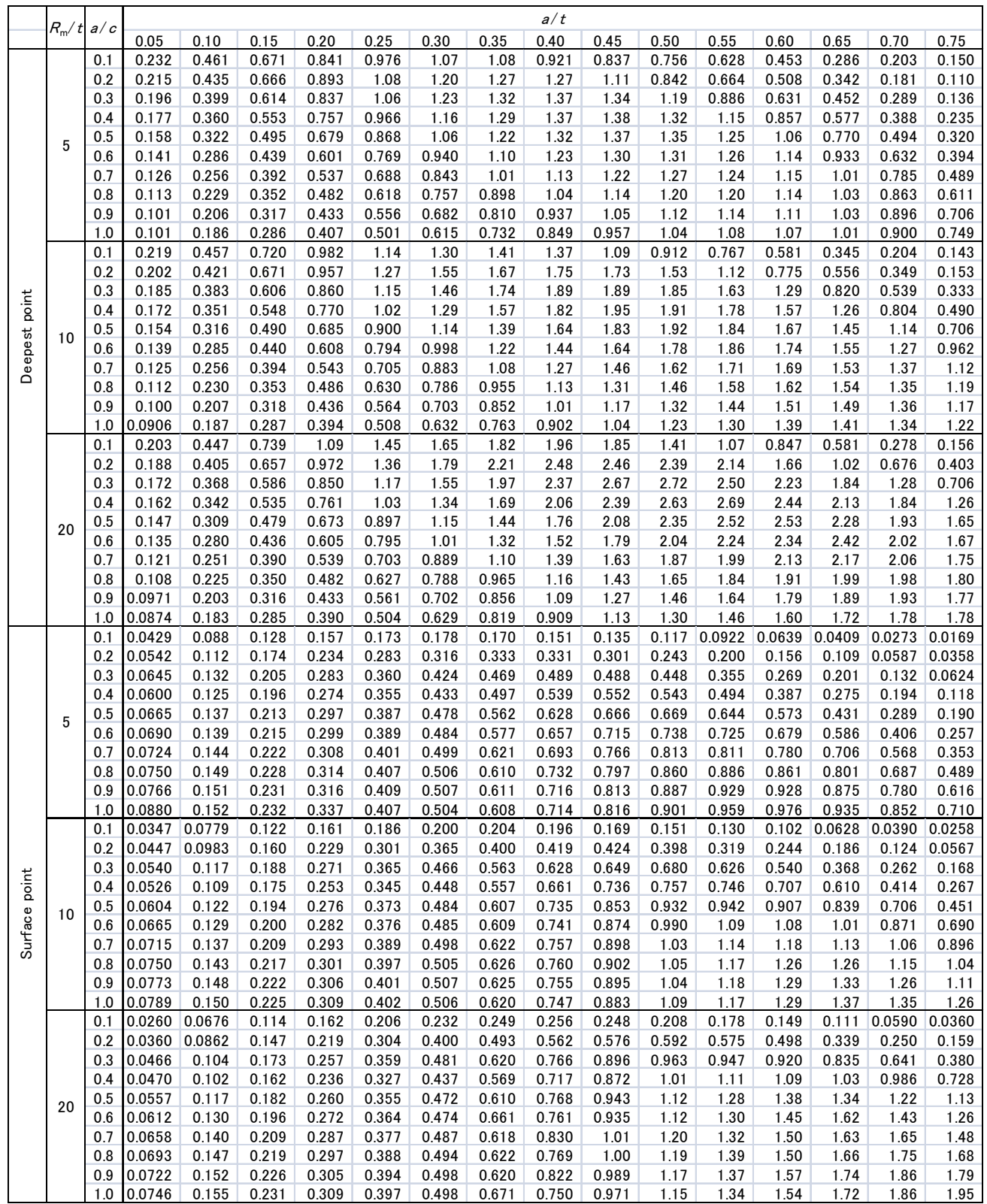

integrity assessments.

Figure 9 shows the J-integral obtained by invoking the non-linear geometry (the NLGEOM) option with ABAQUS in the analysis procedure, although the previous analyses were conducted without the NLGEOM option. This option enables non-linear geometrical change caused by large strain to be considered using the true-stress and strain material properties. Large strain induced by the pressure over the limit pressure may require the NLGEOM option for accurate analyses. From the results shown in Fig. 9, the effect of large strain was not significant for the J-integral calculation up to the pressure of $P / P_{\mathrm{L}}=1.6$. Therefore, the NEGEOM option was not adopted in the following analysis in order to reduce calculation time. 
Table 2(c) Constants $h_{1}$ values for J-integrals $(n=7)$.

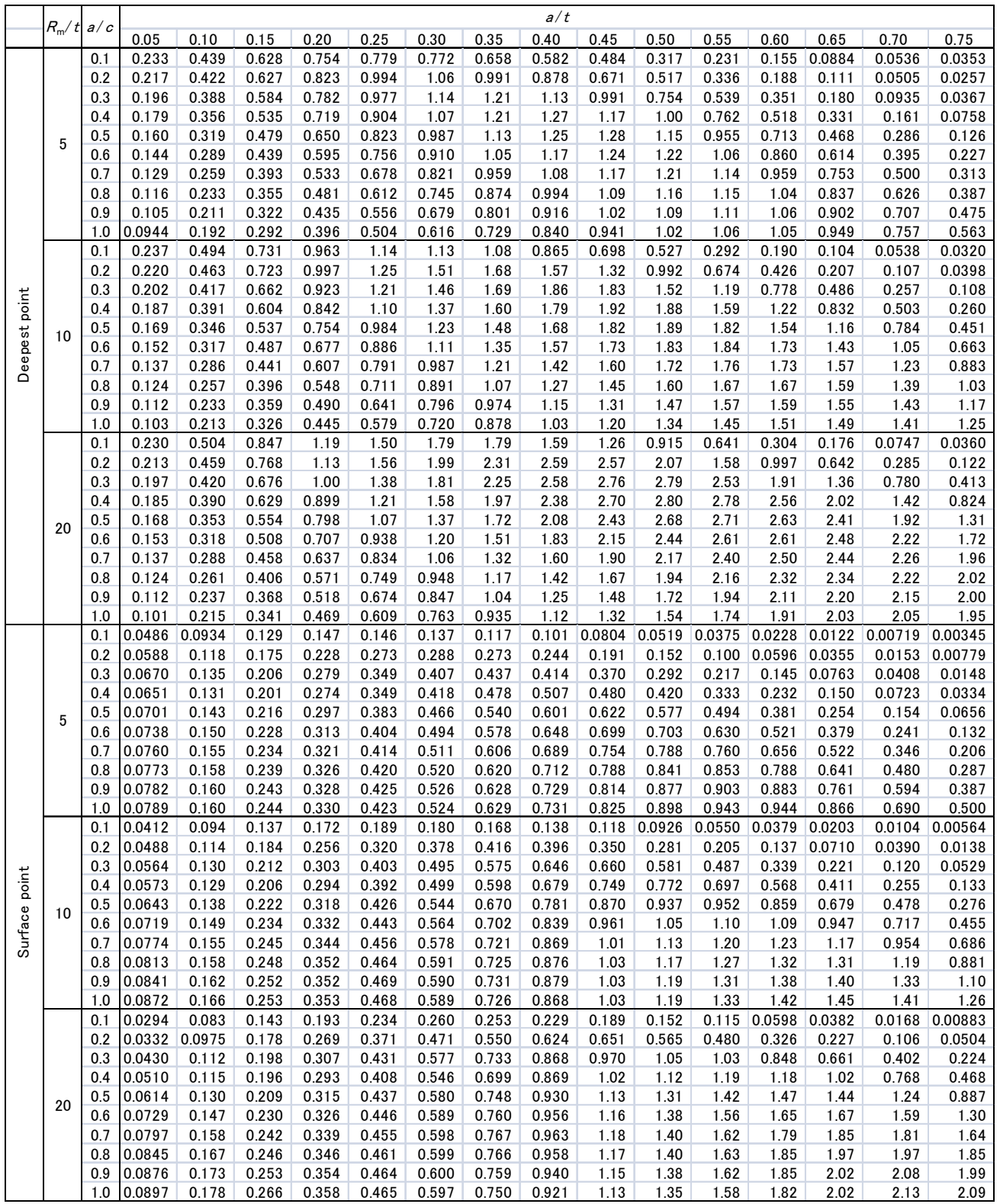

\subsection{Constants $f_{1}$ and $h_{1}$}

The obtained constants $f_{1}$ and $h_{1}$ at the deepest point and the surface point are summarized in Tables 1 and 2, respectively. The value at $\phi=3.8^{\circ}$ was taken as that at the surface point. The number of significant figures was set to three ${ }^{(14)}$. As mentioned, the values were evaluated for 450 geometrical conditions ( 3 for $R_{\mathrm{m}} / t, 15$ for $a / t$ and 10 for $a / c$ ) for each material condition.

\section{Discussion}

\subsection{Error in J-integral estimation}

J-integrals were evaluated additionally assuming the R-O relation for each geometrical and material condition shown in Table 2, and they were compared with those obtained from 
Table 2(d) Constants $h_{1}$ values for J-integrals $(n=10)$.

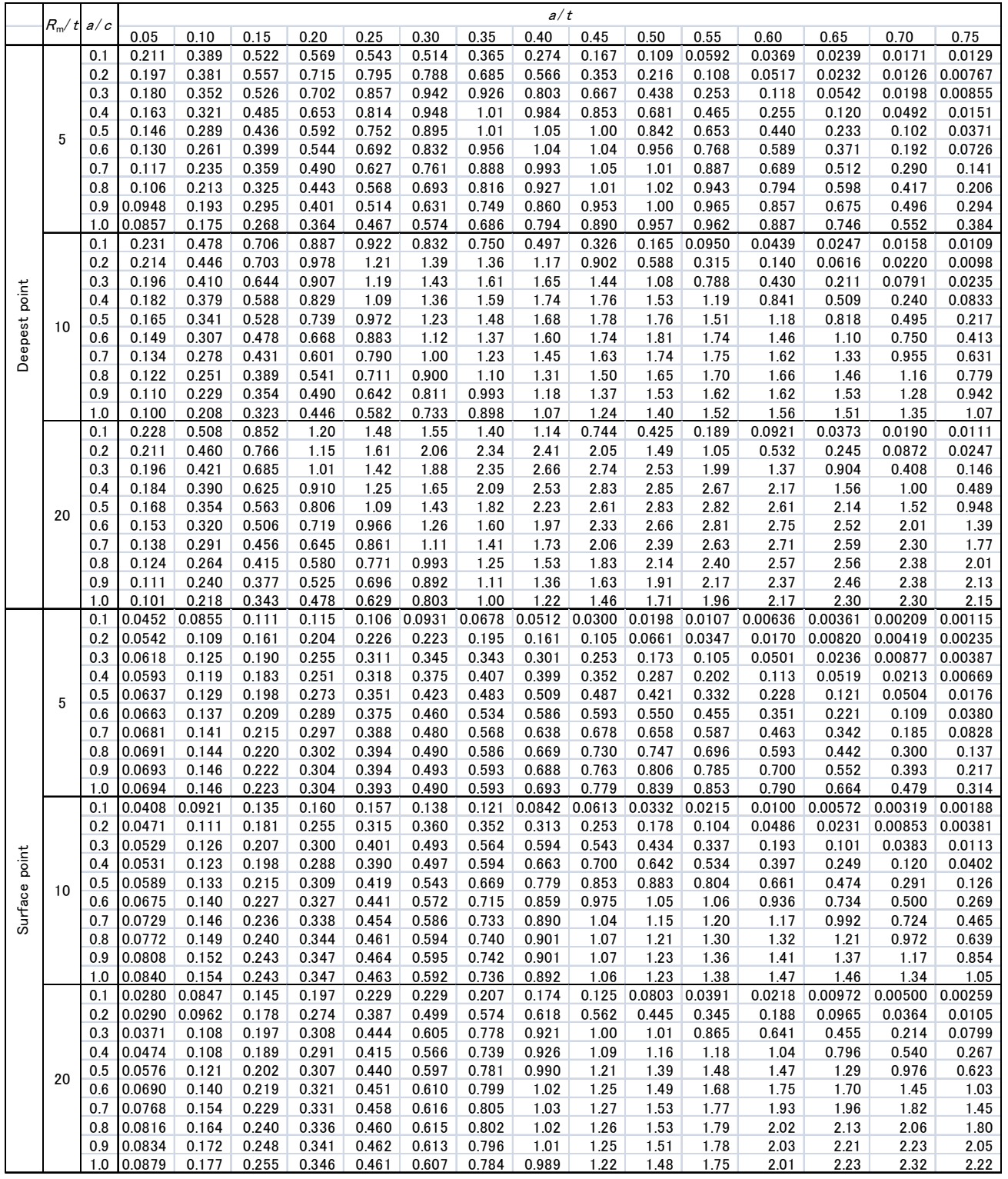

Eqs. (4) and (6) using the constants $f_{1}$ and $h_{1}$. By taking the J-integral for R-O material, $J_{(\mathrm{R}-\mathrm{O})}$, as the basis, the accuracy of the J-integral estimation using the constants in Tables 1 and 2 together with Eqs. (4) and (6) could be evaluated quantitatively. The parameter representing the error in the $\mathrm{J}$-integral estimation was defined as:

$$
F=\frac{J_{\text {est }}-J_{(\mathrm{R}-\mathrm{O})}}{J_{(\mathrm{R}-\mathrm{O})}} \times 100 \% .
$$

The parameter $F$ was calculated for pressures of $0.8 P_{\mathrm{L}}, 1.0 P_{\mathrm{L}}, 1.2 P_{\mathrm{L}}, 1.4 P_{\mathrm{L}}$ and $1.6 P_{\mathrm{L}}$. The maximum pressure assumed in the integrity assessment of the FFS code should be more than $P / P_{\mathrm{L}}=1.5$, because the flow stress, which is defined as the average of the yield and ultimate strength, is $1.5 \sigma_{\mathrm{y}}$ at the maximum for the materials which exhibit the elastic-plastic failure and are used in the primary components (class 1 components) of nuclear power plants. On the other hand, the minimum pressure should be less than $P / P_{\mathrm{L}}=1.0$, because 
Table 2(e) Constants $h_{1}$ values for J-integrals $(n=13)$.

\begin{tabular}{|c|c|c|c|c|c|c|c|c|c|c|c|c|c|c|c|c|c|}
\hline & \multirow{2}{*}{$R_{\mathrm{m}} / t$} & \multirow{2}{*}{$a / c$} & \multicolumn{15}{|c|}{$a / t$} \\
\hline & & & 0.05 & 0.10 & 0.15 & 0.20 & 0.25 & 0.30 & 0.35 & 0.40 & 0.45 & 0.50 & 0.55 & 0.60 & 0.65 & 0.70 & 0.75 \\
\hline \multirow{30}{*}{ 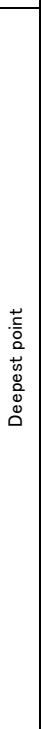 } & \multirow{10}{*}{5} & 0.1 & 0.190 & 0.341 & 0.441 & 0.445 & 0.377 & 0.276 & 0.176 & 0.105 & 0.0561 & 0.0296 & 0.0169 & 0.0115 & 0.00874 & 0.00693 & 0.00534 \\
\hline & & 0.2 & 0.178 & 0.340 & 0.491 & 0.623 & 0.650 & 0.608 & 0.461 & 0.296 & 0.164 & 0.0776 & 0.0299 & 0.0128 & 0.00677 & 0.00444 & 0.00311 \\
\hline & & \begin{tabular}{|l|}
0.3 \\
\end{tabular} & 0.163 & 0.317 & 0.472 & 0.624 & 0.756 & 0.797 & 0.733 & 0.575 & 0.389 & 0.214 & 0.0990 & 0.0389 & 0.0133 & 0.00532 & 0.00292 \\
\hline & & \begin{tabular}{|l|}
0.4 \\
\end{tabular} & 0.148 & 0.290 & 0.436 & 0.586 & 0.727 & 0.841 & 0.865 & 0.789 & 0.629 & 0.423 & 0.236 & 0.109 & 0.0407 & 0.0118 & 0.00397 \\
\hline & & 0.5 & 0.133 & 0.261 & 0.393 & 0.534 & 0.678 & 0.805 & 0.901 & 0.909 & 0.811 & 0.626 & 0.413 & 0.226 & 0.100 & 0.0342 & 0.00831 \\
\hline & & \begin{tabular}{|l|}
0.6 \\
\end{tabular} & 0.119 & 0.238 & 0.364 & 0.496 & 0.630 & 0.754 & 0.864 & 0.934 & 0.888 & 0.770 & 0.565 & 0.363 & 0.191 & 0.0787 & 0.0216 \\
\hline & & 0.7 & 0.106 & 0.214 & 0.329 & 0.448 & 0.573 & 0.696 & 0.810 & 0.903 & 0.939 & 0.853 & 0.711 & 0.498 & 0.300 & 0.144 & 0.0506 \\
\hline & & \begin{tabular}{|l|}
0.8 \\
\end{tabular} & 0.0957 & 0.194 & 0.297 & 0.405 & 0.520 & 0.638 & 0.752 & 0.854 & 0.923 & 0.912 & 0.790 & 0.625 & 0.417 & 0.228 & 0.0954 \\
\hline & & \begin{tabular}{|l|}
0.9 \\
\end{tabular} & 0.0862 & 0.176 & 0.269 & 0.367 & 0.473 & 0.583 & 0.694 & 0.799 & 0.881 & 0.918 & 0.847 & 0.711 & 0.518 & 0.319 & 0.152 \\
\hline & & $\begin{array}{l}.0 \\
\end{array}$ & 0.0779 & 0.160 & 0.245 & 0.334 & 0.429 & 0.531 & 0.637 & 0.741 & 0.831 & 0.889 & 0.873 & 0.765 & 0.607 & 0.404 & 0.217 \\
\hline & \multirow{10}{*}{10} & \begin{tabular}{|l|}
0.1 \\
\end{tabular} & 0.227 & 0.467 & 0.662 & 0.805 & 0.756 & 0.617 & 0.426 & 0.241 & 0.123 & 0.0534 & 0.0241 & 0.0124 & 0.00836 & 0.00624 & 0.00466 \\
\hline & & \begin{tabular}{|l|} 
\\
\end{tabular} & 0.210 & 0.441 & 0.695 & 0.952 & 1.13 & 1.26 & 1.13 & 0.882 & 0.555 & 0.286 & 0.125 & 0.0456 & 0.0150 & 0.00612 & 0.00352 \\
\hline & & 0.3 & 0.193 & 0.406 & 0.640 & 0.902 & 1.17 & 1.37 & 1.50 & 1.47 & 1.16 & 0.776 & 0.441 & 0.206 & 0.0767 & 0.0208 & 0.00587 \\
\hline & & \begin{tabular}{|l|} 
\\
\end{tabular} & 0.179 & 0.377 & 0.588 & 0.829 & 1.09 & 1.36 & 1.54 & 1.63 & 1.60 & 1.27 & 0.903 & 0.538 & 0.258 & 0.0961 & 0.0229 \\
\hline & & \begin{tabular}{|l|}
0.5 \\
\end{tabular} & 0.163 & 0.340 & 0.529 & 0.742 & 0.979 & 1.23 & 1.48 & 1.65 & 1.69 & 1.62 & 1.28 & 0.920 & 0.548 & 0.257 & 0.0880 \\
\hline & & \begin{tabular}{|l|}
0.6 \\
\end{tabular} & 0.147 & 0.306 & 0.481 & 0.675 & 0.899 & 1.15 & 1.40 & 1.62 & 1.73 & 1.73 & 1.61 & 1.25 & 0.874 & 0.499 & 0.215 \\
\hline & & \begin{tabular}{|l|}
0.7 \\
\end{tabular} & 0.133 & 0.276 & 0.433 & 0.607 & 0.806 & 1.03 & 1.27 & 1.49 & 1.66 & 1.73 & 1.68 & 1.50 & 1.14 & 0.750 & 0.390 \\
\hline & & \begin{tabular}{|l|}
0.8 \\
\end{tabular} & 0.120 & 0.250 & 0.391 & 0.547 & 0.725 & 0.923 & 1.14 & 1.36 & 1.55 & 1.68 & 1.69 & 1.59 & 1.34 & 0.982 & 0.587 \\
\hline & & \begin{tabular}{|l|}
0.9 \\
\end{tabular} & 0.109 & 0.228 & 0.356 & 0.496 & 0.654 & 0.833 & 1.03 & 1.23 & 1.42 & 1.58 & 1.65 & 1.61 & & 1.15 & 0.777 \\
\hline & & $\begin{array}{l}.0 \\
\end{array}$ & 0.0993 & 0.208 & 0.324 & 0.450 & 0.593 & 0.753 & 0.928 & 1.11 & 1.30 & 1.46 & 1.57 & 1.58 & 1.49 & 1.27 & 0.937 \\
\hline & \multirow{10}{*}{20} & \begin{tabular}{|l|l|}
0.1 \\
\end{tabular} & 0.230 & 0.515 & 0.865 & 1.20 & 1.41 & 1.34 & 1.11 & 0.708 & 0.371 & 0.163 & 0.0609 & .0235 & 0.0107 & 0.00676 & 0.00478 \\
\hline & & \begin{tabular}{|l|}
0.2 \\
\end{tabular} & 0.213 & 0.466 & 0.784 & 1.19 & 1.67 & 2.10 & 2.26 & 2.21 & 1.68 & 1.07 & 0.572 & 0.252 & 0.0857 & 0.0216 & 0.00679 \\
\hline & & \begin{tabular}{|l|}
0.2 \\
\end{tabular} & 0.199 & 0.426 & 0.703 & 1.05 & 1.48 & 1.98 & 2.45 & 2.67 & 2.61 & 2.27 & 1.63 & 0.983 & 0.494 & 0.189 & 0.0490 \\
\hline & & \begin{tabular}{|l|}
0.4 \\
\end{tabular} & 0.188 & 0.396 & 0.641 & 0.945 & 1.31 & 1.75 & 2.2 & 2.68 & 2. & 2.81 & 2. & 38 & 3 & 0.6 & 0.248 \\
\hline & & \begin{tabular}{|l|}
0.7 \\
\end{tabular} & 0.172 & 0.361 & 0.579 & 0.838 & 1.15 & 1.5 & 1.9 & 2.39 & 2.79 & 2.9 & 2.8 & 2.50 & 1.92 & 1.24 & 0.634 \\
\hline & & \begin{tabular}{|l|}
0.6 \\
\end{tabular} & 0.155 & 0.326 & 0.520 & 0.749 & 1.02 & 1.3 & 1.7 & 2.14 & 2.54 & 2 & 3.0 & 2.82 & 2.47 & 1.83 & 1.15 \\
\hline & & \begin{tabular}{|l|}
0.7 \\
\end{tabular} & 0.140 & 0.297 & 0.471 & 0.670 & 0.909 & 1.1 & 1.5 & 1.8 & 2.26 & 2. & 2. & 2.89 & 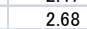 & 5 & 1.60 \\
\hline & & \begin{tabular}{|l|}
0.8 \\
\end{tabular} & 0.126 & 0.270 & 0.427 & 0.606 & 0.01 & & & & & & & & & & 1.95 \\
\hline & & \begin{tabular}{|l|}
0.9 \\
\end{tabular} & 0.114 & 0.246 & 0.388 & 0.548 & 0.736 & 0.95 & 1.20 & 1.4 & 1 & 2.12 & 2.4 & 2.63 & 2.70 & 3 & 2.17 \\
\hline & & 1.0 & 0.103 & 0.224 & 0.354 & 0.496 & 0.665 & 0.860 & 1.08 & 1.33 & 61 & 1.91 & 2.1 & 2.42 & & 2.51 & 2.27 \\
\hline \multirow{30}{*}{$\vec{n}$} & \multirow{20}{*}{10} & \begin{tabular}{|l|}
0.1 \\
\end{tabular} & 0.0411 & 0.0764 & 0.0950 & 0.0908 & 0.0734 & 0.0530 & 0.0346 & 0.0209 & 0.0112 & 0.00611 & 0.00328 & 0.00204 & 0.00128 & 0.000784 & 0.000465 \\
\hline & & \begin{tabular}{|l|}
0.2 \\
\end{tabular} & 0.0490 & 0.0989 & 0.144 & 0.180 & 0.188 & 0.175 & 0.135 & 0.0883 & 0.0503 & 0.0249 & 0.0103 & 0.00474 & 0.00245 & 0.00154 & 0.00095 \\
\hline & & \begin{tabular}{|l|}
0.3 \\
\end{tabular} & 0.0560 & 0.113 & 0.172 & 0.229 & 0.278 & 0.295 & 0.275 & 0.218 & 0.151 & 0.0 & 0.0413 & 0.0167 & 0.0 & & 142 \\
\hline & & \begin{tabular}{|l|}
0.4 \\
\end{tabular} & 0.0534 & 0.108 & 0.165 & 0.226 & 0.286 & 0.335 & 0.351 & 0.321 & 0.260 & 0.182 & 0.104 & 0.0475 & 0.0172 & 0.00516 & 0.00187 \\
\hline & & \begin{tabular}{|l|}
0.5 \\
\end{tabular} & 0.0573 & 0.116 & 0.179 & 0.247 & 0.319 & 0.384 & 0.434 & 0.440 & 0 & 2 & 0.212 & 6 & 0.0 & & 0.00404 \\
\hline & & \begin{tabular}{|l|}
0.6 \\
\end{tabular} & 0.0598 & 0.125 & 0.191 & 0.267 & 0.350 & 0.429 & 0.494 & 0.535 & 0.516 & 0.448 & 0.338 & 217 & 0.110 & 0.0416 & 0.0105 \\
\hline & & \begin{tabular}{|l|}
0.7 \\
\end{tabular} & 0.0610 & 0.129 & 0.198 & 0.276 & 0.363 & 0.453 & 0.534 & 0.595 & & & 0.473 & & & & 0.0275 \\
\hline & & \begin{tabular}{|l|}
0.8 \\
\end{tabular} & 0.0614 & 0.132 & 0.203 & 0.281 & 0.370 & 0.465 & 0.558 & 0.635 & 0. & 0.679 & 0.592 & 68 & 3 & 0.156 & 0.0584 \\
\hline & & \begin{tabular}{|l|}
0.9 \\
\end{tabular} & 0.0619 & 0.1 & & & 0372 & & & 0.660 & & & & & & & 0.105 \\
\hline & & $\begin{array}{l}1.0 \\
\end{array}$ & 0.0620 & 0.134 & 0.206 & 0.283 & 0.370 & 0.467 & 0.571 & 0.668 & 0.750 & 0.798 & 0.789 & 0.689 & 5 & 0.340 & 0.166 \\
\hline & & \begin{tabular}{|l|}
0.1 \\
\end{tabular} & 0.0396 & 0.0901 & 0.127 & 0.1 & & 0.103 & 0.0725 & 0.0449 & 0.0255 & 0.0119 & 0.00621 & 0.00 & & & 0.000766 \\
\hline & & \begin{tabular}{|l|}
0.1 \\
\end{tabular} & 0.0452 & 0.109 & 0.180 & 0.2 & 0.298 & 0.333 & 0.299 & 0.247 & 0.167 & 0.0939 & 0.0439 & 0.0170 & 0.00607 & 0.00250 & 0.00145 \\
\hline & & \begin{tabular}{|l|}
0.2 \\
\end{tabular} & 0.0501 & 0.124 & 0.204 & 0.3 & 0.401 & 0.479 & 0. & 0.539 & 0 & & & $0 . C$ & 0.0 & & 300 \\
\hline & & \begin{tabular}{|l|}
0.4 \\
\end{tabular} & 0.0483 & 0.119 & 0.195 & 0.2 & 0.389 & 0.493 & 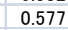 & 0.627 & . & & 17 & 1 & . & 0. & 0.0109 \\
\hline & & \begin{tabular}{|l|}
0.5 \\
\end{tabular} & 0.0534 & 0.128 & 0.211 & 0.307 & 0.420 & 0.543 & 0.668 & 0.766 & 0.815 & 0.819 & 0.694 & 0.523 & 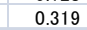 & 0.148 & 0.0480 \\
\hline & & \begin{tabular}{|l|}
0.6 \\
\end{tabular} & 0.0626 & 0.13 & & 0.3 & & & & & 政 & & & & & & 0.135 \\
\hline & & \begin{tabular}{|l|}
0.7 \\
\end{tabular} & 0.0687 & 0.139 & 0.233 & 0.338 & 0.459 & 0.598 & 0.754 & 0.917 & 1. & 1. & 1.1 & 1.10 & 0.865 & 0.569 & 0.282 \\
\hline & & \begin{tabular}{|l|}
0.8 \\
\end{tabular} & 0.0740 & 0.14 & (1.2 & 0.3 & . & 0.607 & & & & & & & & 0.827 & 0.476 \\
\hline & & \begin{tabular}{|l|}
0.9 \\
\end{tabular} & 0.0782 & 0.145 & 0.240 & 0.3 & 0.471 & 0.611 & 0. & & & & 1. & 1 & & 1.07 & 0.696 \\
\hline & & 1.0 & & 0.14 & & 0.3 & & & & & & & & & & & 910 \\
\hline & & \begin{tabular}{|l|}
0.1 \\
\end{tabular} & 0.0265 & 0.0847 & 0.146 & 0.195 & 0.217 & 0.201 & 0.169 & 0.118 & 0.0699 & 0.0347 & 0.0146 & 0.00650 & 0.00296 & 0.00181 & 0.00113 \\
\hline & & \begin{tabular}{|l|}
0.2 \\
\end{tabular} & 0.0238 & 0.0951 & 0.181 & 0.2 & 0.403 & & & & 0.489 & & & & 0.0353 & 00948 & \\
\hline & & \begin{tabular}{|l|} 
\\
\end{tabular} & 0.0290 & 0.105 & 0.199 & & & & & 0.952 & 0.9 & & & 30 & 0.254 & 0.101 & 0.0272 \\
\hline & & \begin{tabular}{|l|}
0.4 \\
\end{tabular} & 0.0452 & 0.101 & 0.186 & 0.293 & 0.426 & 0.589 & 0.778 & 0.974 & 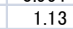 & 1. & 1. & 0.909 & 0.635 & 0.346 & 0.135 \\
\hline & & \begin{tabular}{|l|} 
\\
\end{tabular} & 0.0573 & 0.1 & 0. & & & & & & & & & 1.41 & 1.16 & 0.791 & 0.410 \\
\hline & 20 & 0.6 & 0.0701 & 0.135 & 0.210 & 0.320 & 0.462 & 0.636 & 0.844 & 1.08 & 1. & 1.5 & 1. & 1.79 & & 1.32 & 0.843 \\
\hline & & \begin{tabular}{|l|}
0.7 \\
\end{tabular} & 0.0781 & 0.1 & & & & & & & & & & 2. & 2 & 1.77 & 1.30 \\
\hline & & \begin{tabular}{|l|}
0.8 \\
\end{tabular} & 0.0838 & 0.162 & 0.233 & 0.332 & 0.472 & 0.647 & 0.855 & 1.10 & 1.38 & 1.67 & 1.96 & 2.19 & 2.27 & 2.12 & 1.73 \\
\hline & & \begin{tabular}{|l|}
0.9 \\
\end{tabular} & 0.0883 & 0.1 & 0.242 & 0.3 & 0.4 & 0.6 & 0.8 & 1.0 & 1.4 & 1.6 & & 2.2 & 2.4 & 2.37 & 2.06 \\
\hline & & 1.0 & 0.0910 & 0.180 & 0.251 & 0.339 & 0.465 & 0.631 & 0.833 & 1.07 & 1.34 & 1.64 & 1.95 & 2.24 & 2.46 & 2.52 & 2.32 \\
\hline
\end{tabular}

elastic-plastic failure may occur under the limit pressure.

$F$ values from 11250 cases (450 for geometrical conditions, 5 for $n$ and 5 for applied pressure) are summarized in Figs. 10, 11 and 12. Figure 10 shows the maximum, minimum and average $F$ arranged for applied pressure. The average $F$ was almost zero regardless of applied pressure. As shown in Fig. 7, the effect of applied pressure on J-integral could be considered by the current estimation procedure and the correction by Eq. (6) gave a good estimation. However, the minimum $F$ was less then $-30 \%$, and in particular, it was less than $-60 \%$ at the surface point and it tended to be small near $P=1.2 P_{\mathrm{L}}$. The minimum $F$ is important for the structural integrity assessment because underestimated J-integrals may result in a non-conservative evaluation. The maximum $F$ was almost $20 \%$ for all applied pressures.

The parameter $F$ was arranged for $n$ and $a / c$ in Figs. 11 and 12, respectively. The minimum $F$ decreased and the maximum $F$ increased as $n$ increased, although the average $F$ hardly depended on $n$. As for the influence of $a / c$, the magnitude of $F$ was small for small $a / c$ at the surface point, although the average $F$ at the deepest point was almost constant. 


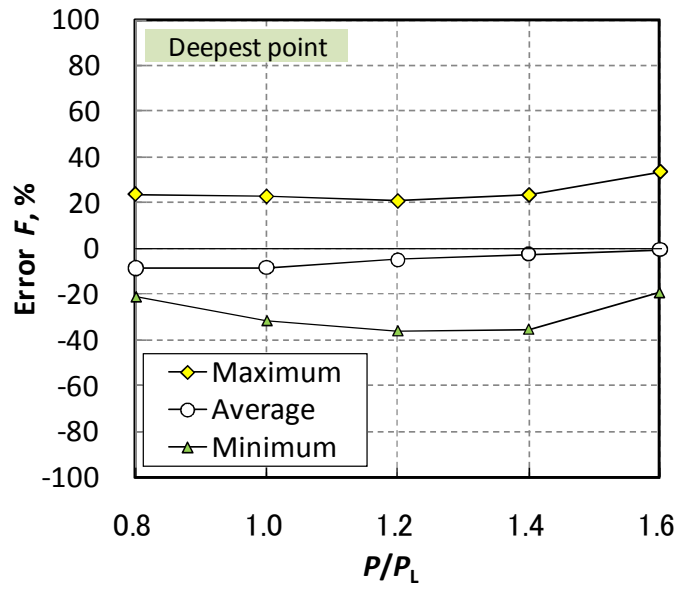

(a) Deepest point

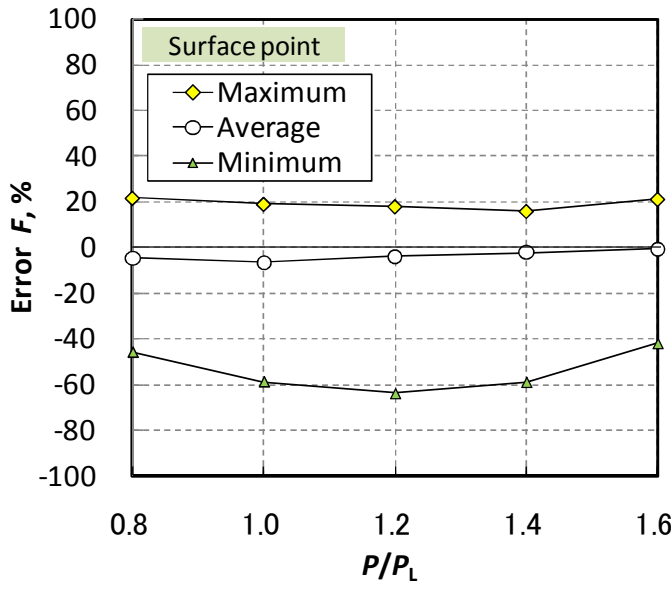

(b) Surface point

Fig. 10 Error in estimation of J-integral (effect of applied pressure).

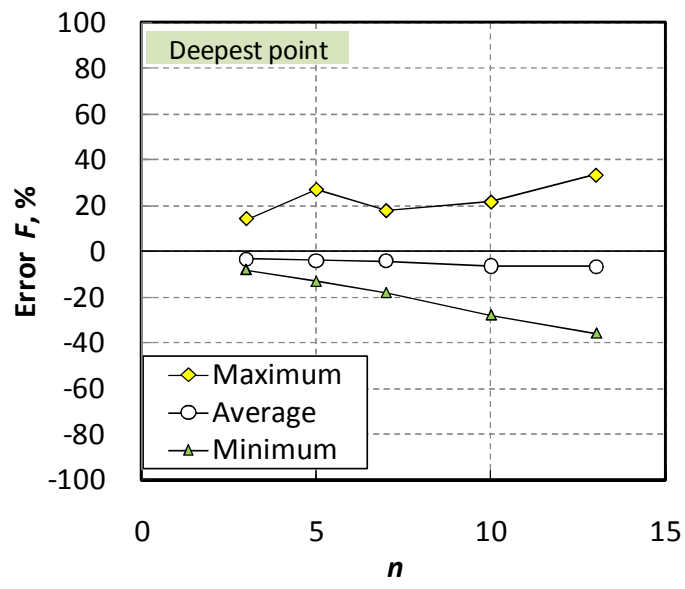

(a) Deepest point

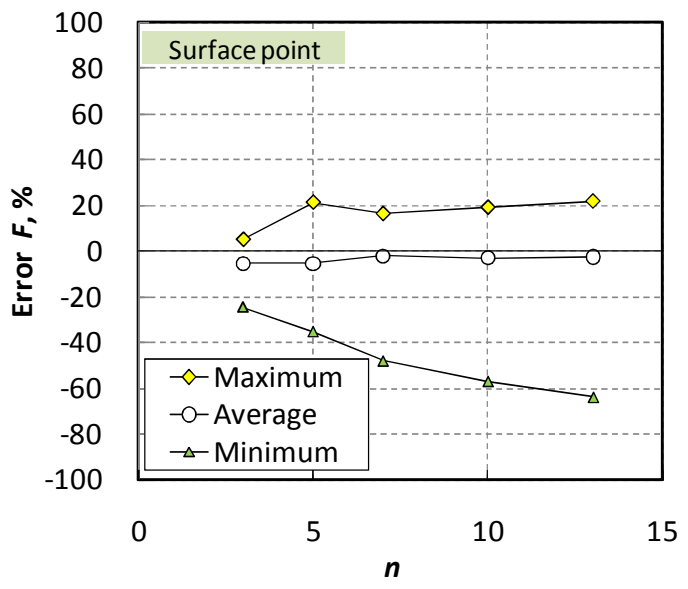

(b) Surface point

Fig. 11 Error in estimation of J-integral (effect of strain hardening exponent).

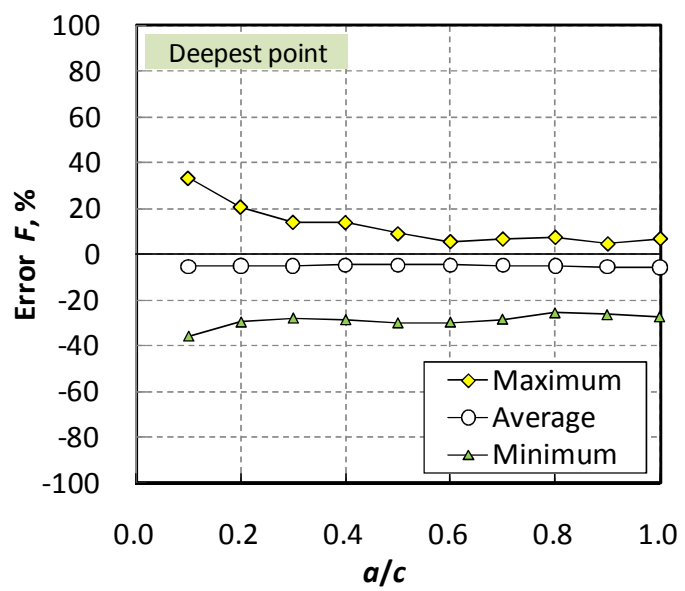

(a) Deepest point

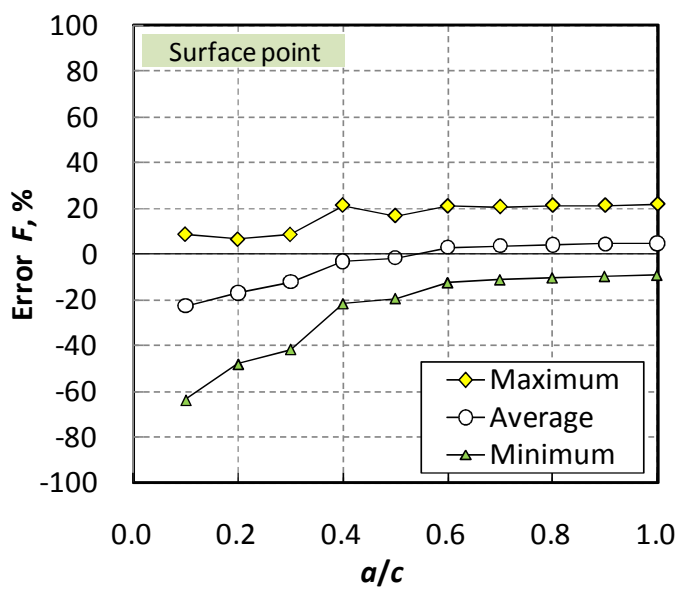

(b) Surface point

Fig. 12 Error in estimation of J-integral (effect of crack shape).

Thus, the large error in the minimum $F$ at the surface point was brought about by the error for large $n$ and small $a / c$.

Figure 13 shows the J-integrals with applied pressure for the maximum $F$ case $(33.5 \%$ when $\left.P / P_{\mathrm{L}}=1.6\right)$ and minimum $F$ case $\left(-35.9 \%\right.$ when $\left.P / P_{\mathrm{L}}=1.2\right)$ at the deepest point, for 


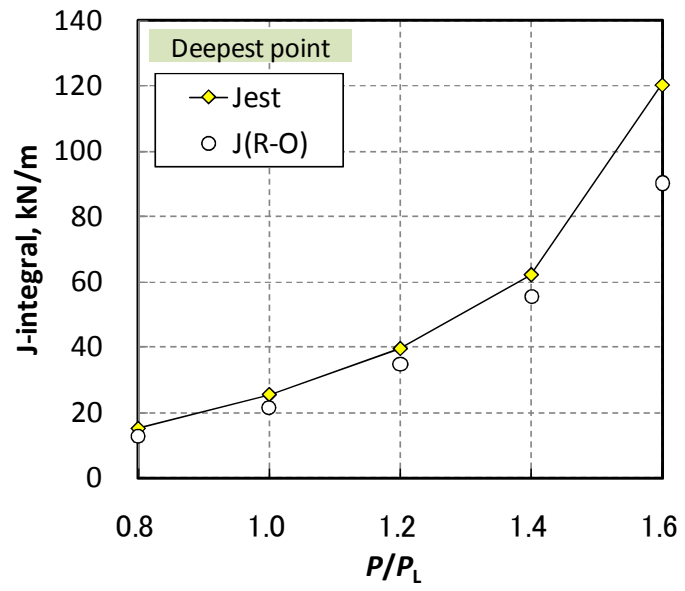

(a) Maximum error $(F=33.5 \%)$

$\left(P / P_{\mathrm{L}}=1.6, n=13, R_{\mathrm{m}} / t=20, a / t=0.75, a / c=0.1\right)$

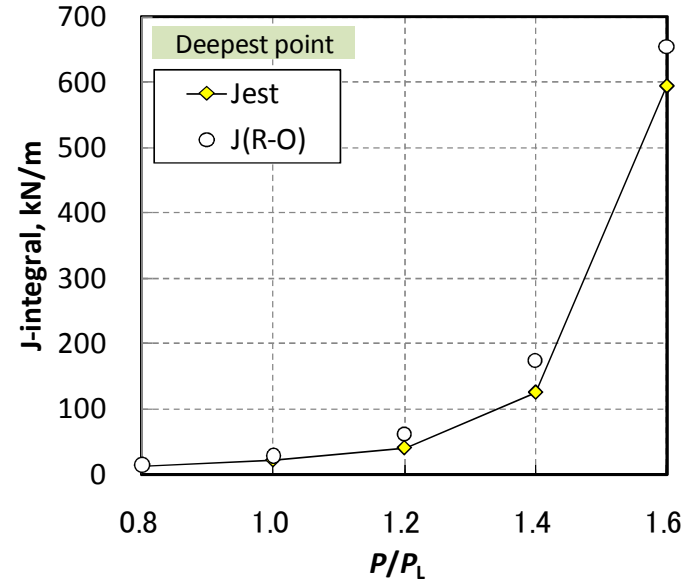

(b) Minimum error $(F=-35.9 \%)$

$\left(P / P_{\mathrm{L}}=1.2, n=13, R_{\mathrm{m}} / t=5, a / t=0.45, a / c=0.1\right)$

Fig. $13 \mathrm{~J}$-integral at the deepest point for which the conditions showed the maximum and minimum errors.

which the respective conditions were $\left(n=13, R_{\mathrm{m}} / t=20, a / t=0.75, a / c=0.1\right)$ and $(n=13$, $\left.R_{\mathrm{m}} / t=5, a / t=0.45, a / c=0.1\right)$. In spite of the steep change in the J-integral with $P / P_{\mathrm{L}}$, the current estimation gave a good approximation. The magnitude of error was not so significant compared with the difference in J-integral with the reference data, which are shown in Figs. 5 and 6. In plant piping systems, the cap effect may reduce the actual J-integrals, although the effect was not considered in $J_{\text {est }}$. The magnitude of the maximum and minimum $F$ became large as $n$ increased. In the integrity assessment, even if the error in J-integral estimation is large for large $n$, the error in the evaluation of allowable pressure is not notable, because the error in the J-integral estimation is proportional to the $(n+1)^{\text {th }}$ power of that in the allowable pressure evaluation. As shown in Eq. (2), the J-integral is proportional to $P^{\mathrm{n}+1}$. For example, in the case of $n=13$, the error in the estimation of $F=$ $-60 \%$ results in approximately $6 \%$ error in the pressure evaluation, and this is less than the safety factor considered in the integrity assessment in the JSME FFS code, which is 3.0 for normal and upset conditions (service conditions $\mathrm{A}$ and $\mathrm{B}$ ) and 1.5 for emergency and faulted conditions (service conditions $\mathrm{C}$ and $\mathrm{D}$ ).

\section{Conclusions}

In order to provide J-integral solutions for assessing the structural integrity of cracked pipes of nuclear power plants, FEA was conducted for semi-elliptical axial surface cracks under internal pressure. First, validity of the finite element mesh and analysis procedure was shown. It was also shown that the cap effect reduced J-integral and NLGOM option had little effect. Then, elastic and fully plastic solutions were obtained for a wide range of geometrical and material conditions, 2250 cases in total. The accuracy of the J-integral estimation using the obtained constants and the applicability to the materials following the Ramberg-Osgood constitutive equation were confirmed through additional FEA for non-linear elastic materials under various magnitudes of pressure. It was revealed that the estimated J-integrals were suitable for structural integrity assessments regardless of material and geometrical conditions and magnitude of the pressure, although they tended to be relatively small when the strain hardening exponent $n$ was large and $a / c$ was small. The maximum error in failure pressure derived using the obtained J-integral solutions was $6 \%$. 


\section{References}

(1) JSME Fitness-For-Service Code S NA1-2008, (2008), The Japan Society of Mechanical Engineers.

(2) Paris, P. C., Tada, H. and Zahoor, A, The Theory of Instability of the Tearing Mode of Elastic-Plastic Crack Growth, In: Elastic-Plastic Fracture (Eds by J. D. Landes, J. A. Begley and G. A. Clarke), ASTM STP 668 (1979), pp. 5-36.

(3) Fitness-For-Service (API 579), (2000), American Petroleum Institute.

(4) ASME Boiler and Pressure Vessel Code Section XI, (2010), American Society of Mechanical Engineers.

(5) Guide to Methods for Assessing the Acceptability of Flaws in Metallic Structures BS7910, (2005), BSI.

(6) Ductile Fracture Handbook, EPRI NP-6301 (1989), Electric Power Research Institute.

(7) Advances in Elastic-Plastic Fracture Analysis, EPRI NP-3607 (1984), Electric Power Research Institute.

(8) Kim, Y. J., Kim, J. S., Park, Y. J. and Kim, Y. J., Elastic-plastic Fracture Mechanics Method for Finite Internal Axial Surface Cracks in Cylinders, Engineering Fracture Mechanics, Vol. 71 (2004), pp.925-944..

(9) Kim, Y. J., Oh, C. S. and Song, T. K., Net-section Limit Pressure and Engineering J Estimates for Axial Part-through Surface Cracked Pipes, Proc. 2007 ASME Pressure Vessels and Piping Division Conference, (2007), No. 26220.

(10) Hutchinson, J. W., Plastic Stress and Strain Fields at a Crack Tip, J. Mech. Phys. Solids, Vol. 16 (1968), pp. 337-347.

(11) Goldman, N. L. and Hutchinson, J. W., Fully plastic crack problems: The center-cracked strip under plane strain, International Journal of Solids and Structures, Vol. 11 (1975), pp. 575-591.

(12) Shih, C. F., J-integral Estimates for Strain Hardening Materials in Antiplane Shear using Fully Plastic Solution, In: Mechanics of Crack Growth, ASTM STP 590 (1976), pp. 3-26.

(13) Kumar, V. and Shih, C. F., Fully Plastic Crack Solutions, Estimation Scheme, and Stability Analyses for the Compact Specimen, In: Fracture Mechanics: Twelfth Conference, ASTM STP 700 (1980), pp. 406-438.

(14) Kamaya, M., J-Integral Solutions for Surface Crack Inside Pipe under Bending Load, Journal of Solid Mechanics and Materials Engineering, Vol. 3 (2009), pp. 1115-1126.

(15) Kamaya, M. and H. Machida, Applicability of Reference Stress Method for J-integral Evaluation to Failure Assessment Curve, Transactions of the Japan Society of Mechanical Engineers, Vol. 75 (2009), pp. 333-342.

(16) Raju, I. S. and Newman, J. C., Jr., Stress-Intensity Factors for Internal and External Surface Cracks in Cylindrical Vessels, Tran. ASME, Ser. J, Journal of Pressure Vessel Technology, Vol. 104 (1982), pp. 293-298.

(17) Newman, J. C., Jr. and Raju, I. S., Stress-Intensity Factors for Internal Surface Cracks in Cylindrical Vessels, Tran. ASME, Ser. J, Journal of Pressure Vessel Technology, Vol. 102(1980), pp. 342-346. 